\title{
ALGORITHM FOR AUTOMATIC COMPENSATION OF VOLTAGE DIPS IN POWER SUPPLY OF INDUSTRIAL FACILITIES
}

\author{
Vadim Malarev, Ivan Bogdanov*, Nikita Senchilo

\section{St. Petersburg mining university, Saint Petersburg, Russian Federation}

The factors of failures and their impact on the equipment of large enterprises is discussined in this article. The optimal method for compensating voltage dips was selected and the principle of operation of the developed compensator operation algorithm is described. According to the algorithm, a model was developed at the MatLab Simulink environment. The graphs of the model are presented.

Key words: voltage dip, automatic control system, quality of electro supply, dynamic compensator of voltage distortion

\section{INTRODUCTION}

The power supply quality and reliability are some of the most important energy issues in the modern world. They are sectored and are standardized by GOST 32144 2013. A number of tasks are set to execute the regulatory requirements [1].

One of these similar tasks is a task about the voltage dips elimination or compensation. A voltage dip is usually associated with the occurrence and ending of a short circuit or other emergency mode, also with connecting a powerful consumer to the electrical network [2-4]. In accordance with the requirements of this standard, a voltage dip is considered as electromagnetic interference, the intensity of it is determined by both voltage and duration. The duration of the voltage dip can be up to $1 \mathrm{~min}$.

In three-phased power supply systems, the moment when the voltage drops is taken as the beginning of the voltage dip. This moment is when in one of the phases the threshold value of the voltage dip starts falling below and the time when the voltage in all phases rises above the threshold value of the voltage dip end is taken to be the end of the voltage dip.

Such failures contribute the disruption of technological processes complex with false alarms of the power grid automation and protection system, power failures of a special group of consumers of the first category and significant economic damage. Besides, the non-sinusoidal load entails the appearance of harmonic voltage distortions.

Different equipment has acceptable limits of voltage dropping as a percentage from the nominal, at which the equipment remains operational. With a voltage drop of up to $60 \%$ for a duration of $0.5 \mathrm{~s}$, the performance of general equipment is maintained. Motors with electronic control and sophisticated computer technology are more sensitive to voltage dips, and acceptable dips are a $10 \%$ decrease in voltage values of $0.05 \mathrm{~s}$ duration [5].

According to the US Electric Power Research Institute (EPRI), voltage sensitivity thresholds for some systems and devices of the electrical complex are identified:

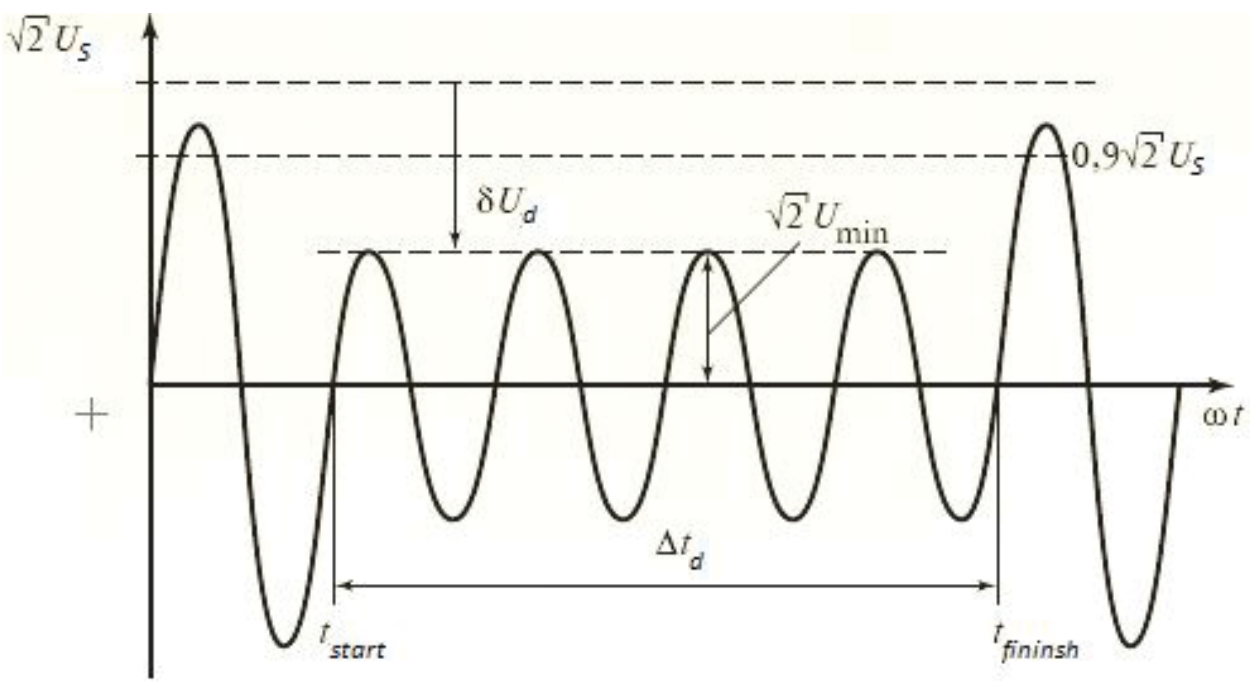

Figure 1: voltage dip with depth $\delta U d$ and duration $\Delta t d$ 


\begin{tabular}{|c|c|c|}
\hline Equipment type & Residual voltage, $\%$ & Maximum failure duration, mc \\
\hline Motor starter & 50 & 40 \\
\hline Variable speed engine & 85 & 10 \\
\hline Programmable logic controller & $50-90$ & $8-20$ \\
\hline Frequency converter & 82 & 1,5 \\
\hline Adjustable electric drivers & $50-80$ & $2-3$ \\
\hline Process controller & 70 & $<8$ \\
\hline CNC machines & 70 & $<8$ \\
\hline DC drive controller & 88 & $<8$ \\
\hline Personal computers & $50-70$ & $60-160$ \\
\hline Contactors & $50-60$ & $20-30$ \\
\hline Electromagnetic switcher & 50 & 10 \\
\hline Electromagnetic relay & $50-60$ & $15-40$ \\
\hline Medical equipment & 60 & 130 \\
\hline
\end{tabular}

\section{METHODS}

There are various ways to maintain the required voltage level in the electrical network. Main ones are:

- Uninterruptible power supplies (UPS);

- Energy storage by capacitors (ESC);

- Static synchronous compensator (STATCOM);

- DC voltage regulators;

- Active voltage regulators;

- Dynamic voltage restoration (DVR).

For example, UPSs are widely used for powering special critical consumers requiring uninterrupted power supply, also trouble-free shutdown, but the high price of their installation and maintenance does not allow their use everywhere. Voltage stabilizers are used for small single-phase consumers. A feature of stabilizers is low speed, which excludes the possibility of their using for large consumers with high requirements for the duration of failure.

The most popular in the solution are the dynamic voltage drop compensators. Such compensator is a device whose input is connected to the power supply system through double voltage conversion. The output through the inverter and through the boost booster transformer is connected to a three-phase load. The secondary winding of the boost booster transformer is connected with the load and compensates for voltage dips in the power supply system [6-9].

The control system permanently monitors the voltage level and compares it with the desired voltage level. If the actual voltage level is lower than the required level, the source converter instantly introduces the differential voltage and maintains the rated voltage on the load side. DVR is used to compensate the effects of voltage dips at sources supplying power to particularly sensitive consumers. Normal power supply is also carried out in case of voltage dips in the power supply system, due to the fact that $D C B$ regulates the load voltage, bringing it closer to the nominal value and disconnecting the ESC from the power system provides a response to a voltage dip in 1-2 ms with subsequent voltage regulation by half for $1 \mathrm{~ms}$ and a complete voltage recovery in $10 \mathrm{~ms}$. DVR provides full compensation for the voltage dip within the nominal range for current overloads of $200 \%$ for at least $30 \mathrm{~s}$, partial compensation for three-phase voltage dips up to $50 \%$ and single-phase dips up to $55 \%$ for at least $30 \mathrm{~s}$ [10].

Existing methods of dynamic voltage compensation are discussed below. Full compensation method. In this method, the calculation of the necessary phase to maintain the initial voltage vector is presented. If a phase jump has not occurred, then compensation occurs only in the amplitude of the vector. The phase changes presence can significantly affect on the added power and voltage of the DC voltage. A phase jump during a dip increases the amplitude of the missing voltage.

Not only the amplitude compensation but also the phase of the voltage vector is an advantage of this method, es-

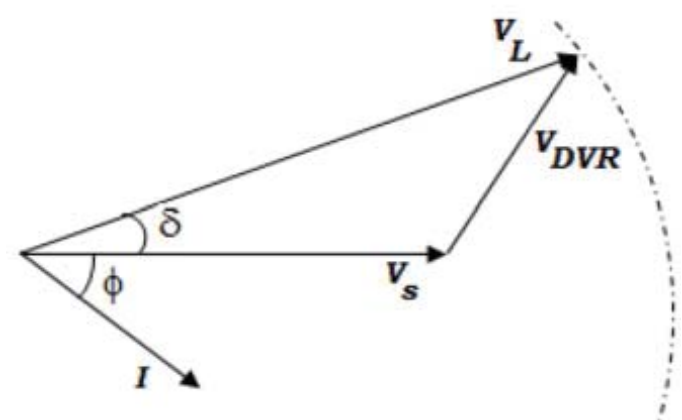

Figure 2: Full compensation method vector diagram 
pecially in cases where some consumers are equipment that is sensitive to a phase change, which includes, for example, loads synchronized with the frequency of the supply voltage.

Common mode compensation method. The common-mode compensation method, unicle to full compensation, is the restoration of the voltage dip only by the amplitude of its vector. In other words, the voltage vector which is added to the DVR network is always in phase with the voltage vector after the failure.

During the normal operation of the power system, the load and network voltages have the same phase shift relative to the current, respectively; the phase difference between these voltage vectors is zero.

However, when the voltage drops, a phase jump of the vector will be observed along with a decrease in its modulus. Thus, the compensated voltage will be an excellent phase shift from the desired voltage at the load.

The advantages of this method include the energy consumption minimizing of the DC link in comparison with the method of full compensation.

Reactive compensation method. This method might be attributed to a particular common-mode compensation method, since the additional voltage vector is collinear with the imaginary component of the network voltage vector (reactive component). Due to this, a zero consumption of active energy of the dynamic compensator is achieved, that is, it is even less than in the case of the common-mode compensation method.

This method finds application, mainly, only for small voltage distortions. It cannot be used in the case of deep and long-term dips due to a sufficiently high load consumption of active power. However, it might be useful when the energy storage charge is low.

The combined method. It implies a combination of basic compensation methods in various situations, combining the advantages of each method, thereby achieving the highest efficiency of the DVR functioning.

Different control methods might be used to compensate for symmetrical voltage dips. All methods might be used for DVR and used in various conditions. The full compensation method is more appropriate to use during minor dips, and the in-phase compensation method is for heavier dips with a phase jump.

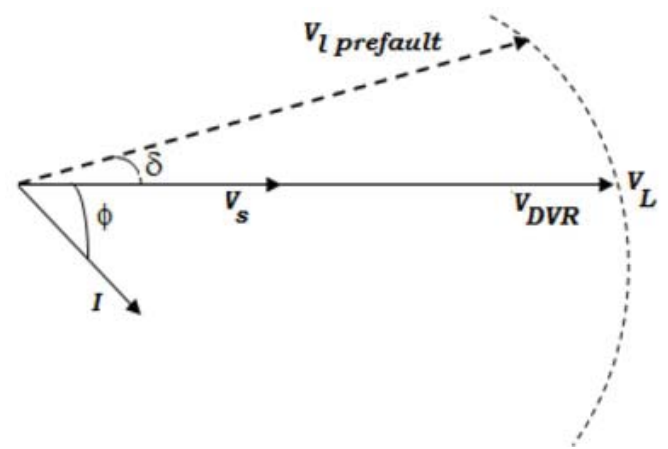

Figure 3: Common mode compensation vector diagram

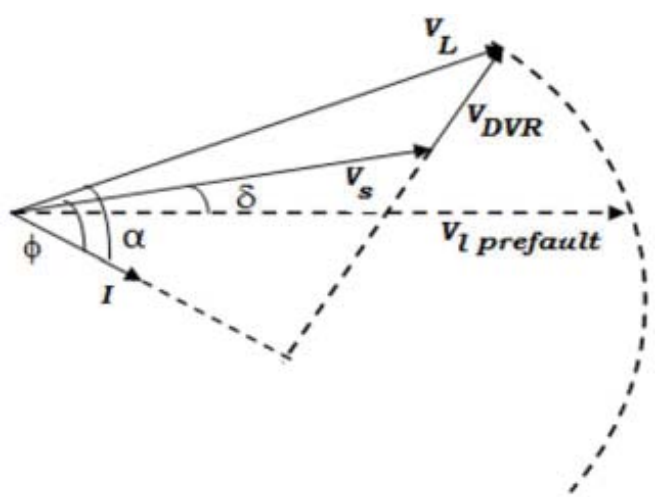

Figure 4: Reactive compensator vector chart

Reactive compensation makes sense only under certain conditions. Also, it is required to calculate the compensation device for a voltage of a higher nominal value, and a large phase shift of the voltage is introduced by the DVR, even when the failure occurs without a phase jump.

For maximum efficiency and adaptability, the automatic control system is implemented on the basis of fuzzy-logic with the possibility of combining all the considered methods. Using the illegible logic is conditioned by the possibility of flexible reconstruction of the DKPN operation, which is using the described above methods during the following, occur changes in the network parameters:

- $\quad$ changing the amplitude value voltage $\Delta U_{-} s m$;

- the phase angle jump $\Delta \varphi$;

- failure duration $\Delta \mathrm{t}$.

During managing the network parameters, measuring devices and regulators are required to generate the necessary voltages on the load. The control element must be resistant to various interferences, both from the network side and from the load side. Disturbing influences here may be, for example, unbalanced loads or unbalanced supply voltages.

The perturbation voltage regulator is dominant in the voltage control of the DC voltage circuit because of its simplicity and reliability. According to the measured mains voltage and the desired load voltage, it is possible to calculate the required voltage value in the DVR. Taking into account the actual current of the inverter, the expected voltage drop across the filter is calculated and, based on this, the reference voltage for the DVR controller.

Deviation control involves using of a feedback signal, represented by the voltage at the load or the additional voltage of the dynamic compensator. This principle has a fairly fast and accurate regulation, however, the configuration of voltage controllers is complex and depends on the connected load. Inverter currents do not need to be included to the control system, since the voltage drop in the filtering link in this case is taken into account by the controller. The mains voltage is also measured in order to detect voltage dips, its distortion and frequency for synchronization.

In this case, it is proposed to use a combined scheme that combines several regulatory methods. 


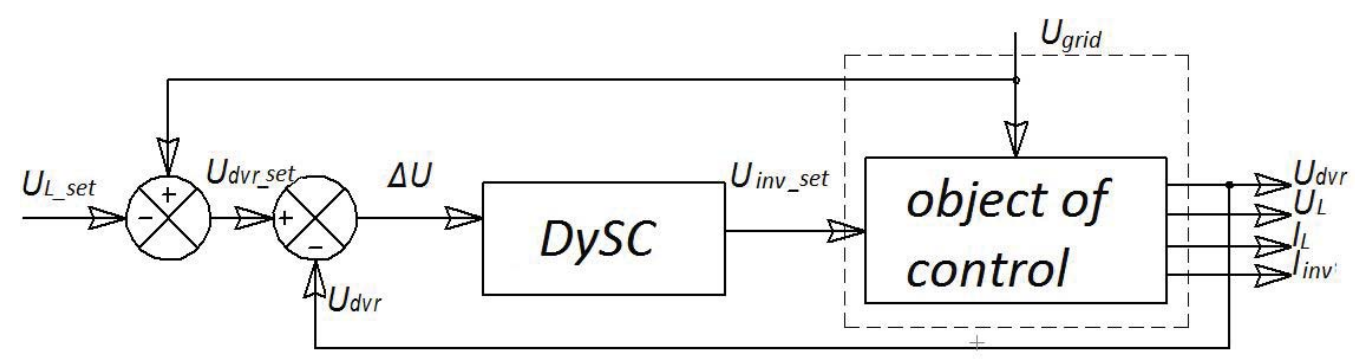

Figure 5: Combined control system

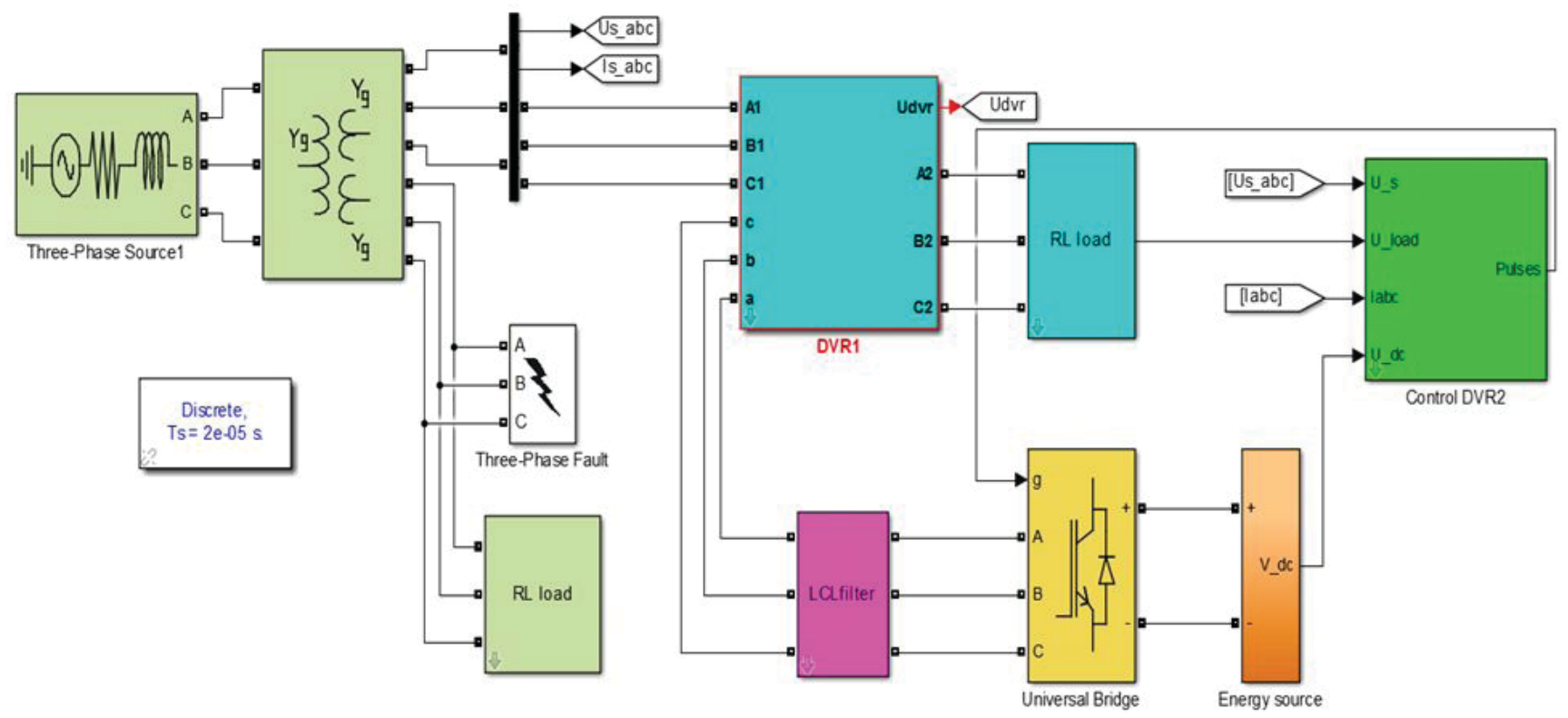

Figure 6: Diagram of a power supply network model with a dynamic sequential type compensator

\section{RESULTS}

As a result, a power supply network model with a sequential-type dynamic compensator was designed and designed in the MatLab Simulink environment, com- bining vector settings, filtercompensating devices, and fuzzy logic $[11,12]$. The scheme of the obtained model is shown in Figure 6.

In this scheme, the main control element Control DVR2 is presented as follows:

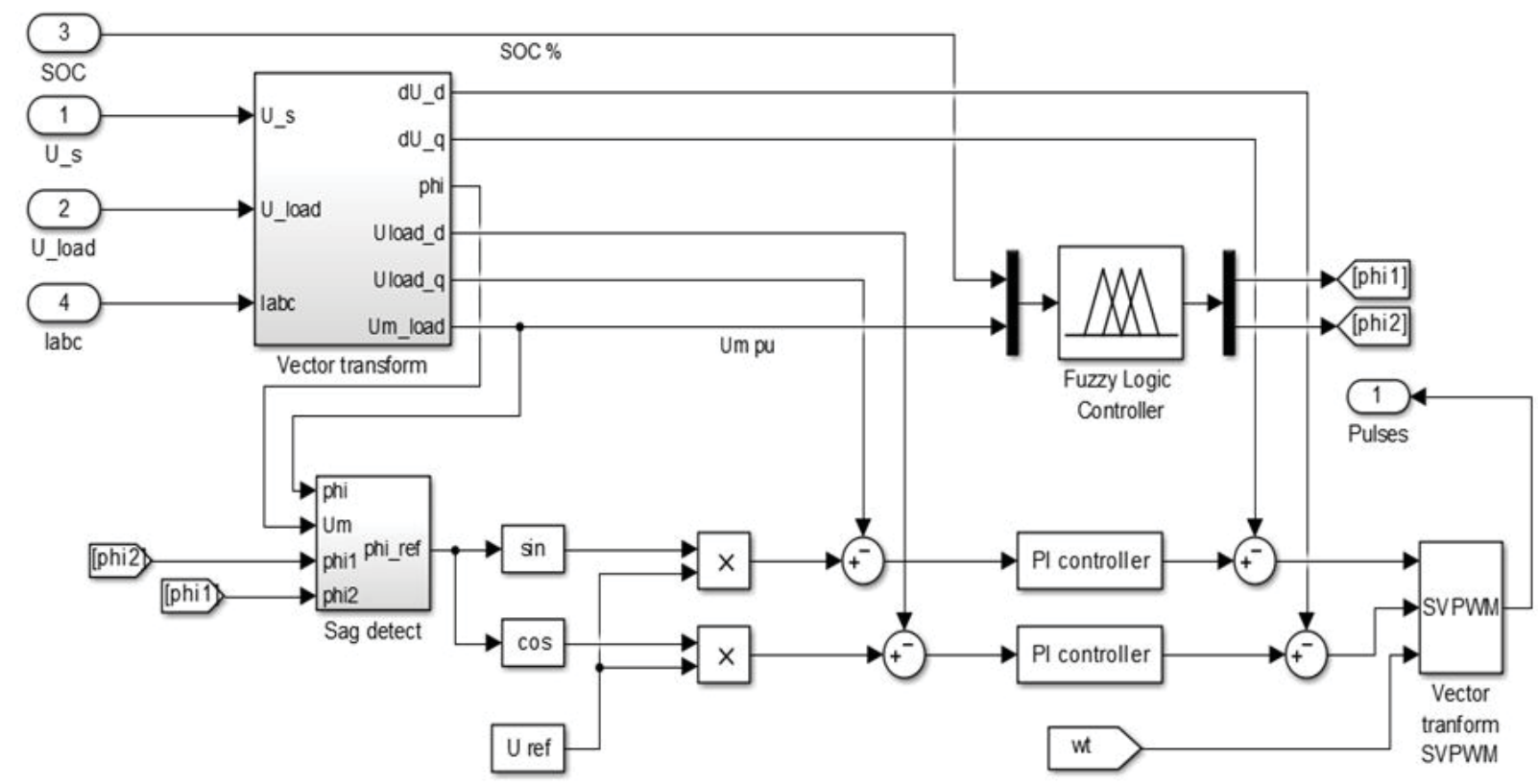

Figure 7: Functional diagram of a control system with a fuzzy phase regulator 


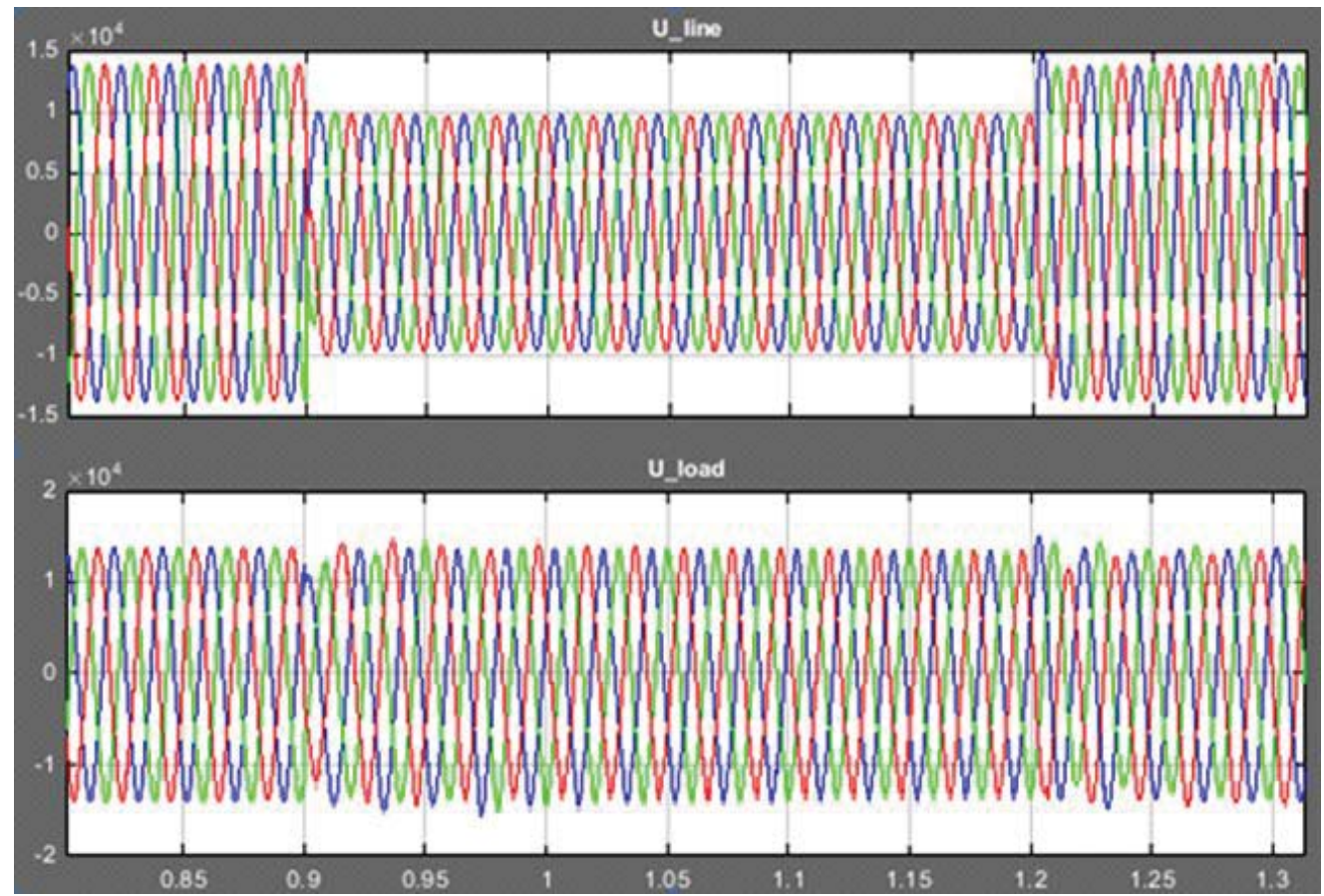

Figure 8: Mains and load voltage

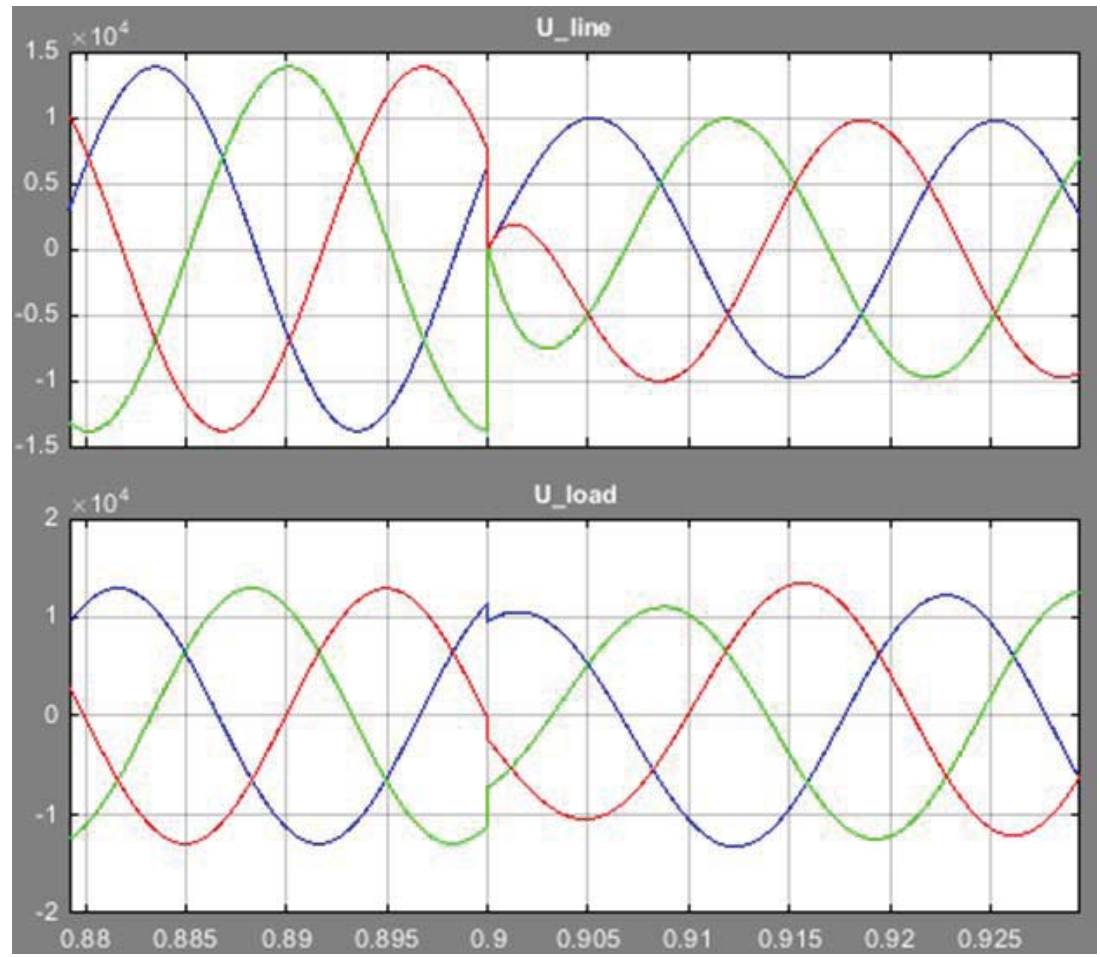

Figure 9: Voltage phase shift compensation

\section{DISCUSSION}

The measured voltages on the waveforms are linear, the amplitude of which in normal operation is $14.1 \mathrm{kV}$. The transient failure compensation process takes $15 \mathrm{~ms}$, while the overshoot does not exceed $5 \%$.

The voltage dip in this case is accompanied by a phase jump, the failure compensation is carried out by the method of full compensation, so the phase jump is al- most completely compensated by the automatic control system.

The common-mode failure compensation method in this case wouldn tless effective; however, the voltage phase jump would be present in the load.

The reactive compensation method is the most effective method for reactive loads. In this case, the power factor is 0.8 , at which the required value of the additional voltage is higher than the capabilities of the dynamic compensator. Therefore, the voltage dip is compensated with 
a static error and a phase jump, but with no active power costs.

During the simulating a single-phase voltage dip, the measured voltages on the waveforms are linear, the amplitude of which in normal operation is $14.1 \mathrm{kV}$. The tran- sient failure compensation process takes $10 \mathrm{~ms}$, while overshooting does not exceed $5 \%$. However, there is a static error within $4.5 \%$, which is acceptable for such systems. A single-phase voltage dip was $50 \%$ of the nominal and had a duration of $200 \mathrm{~ms}$.

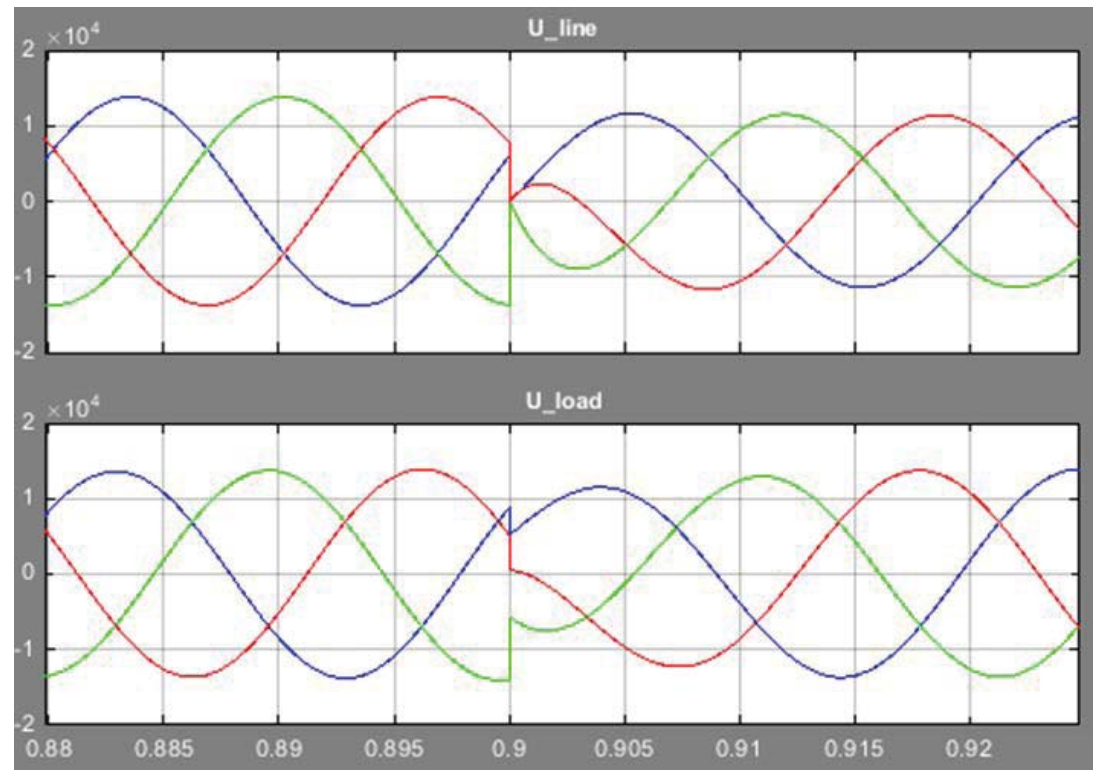

Figure 10: Voltage dip compensation common mode

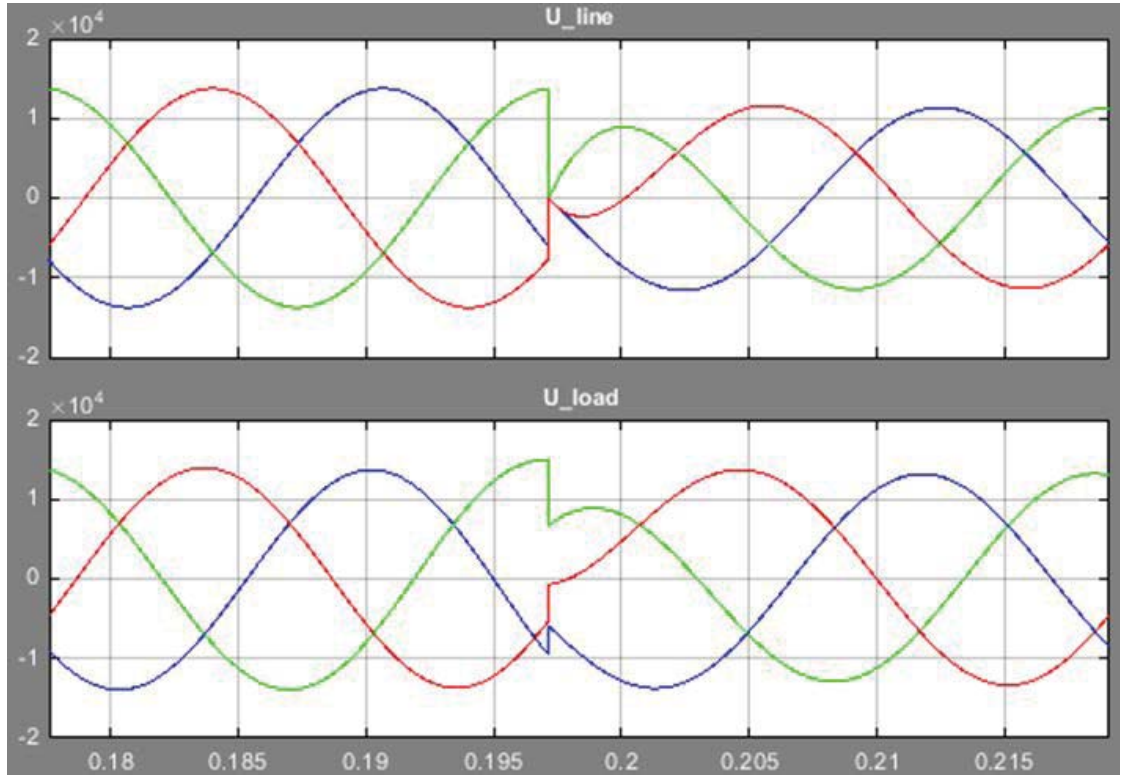

Figure 11: Reactive voltage dip compensation

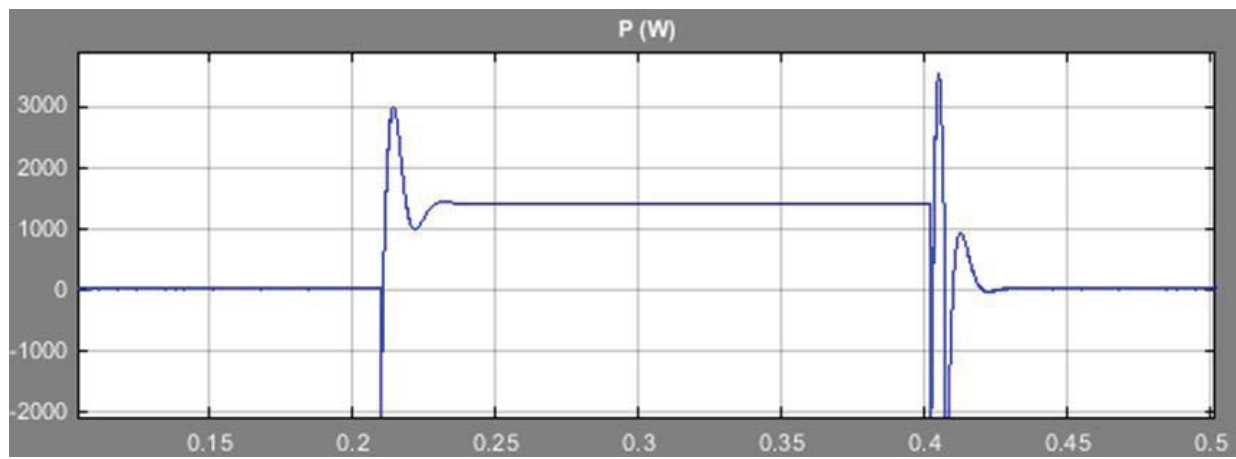

Figure 12: Active DVR power with reactive compensation 


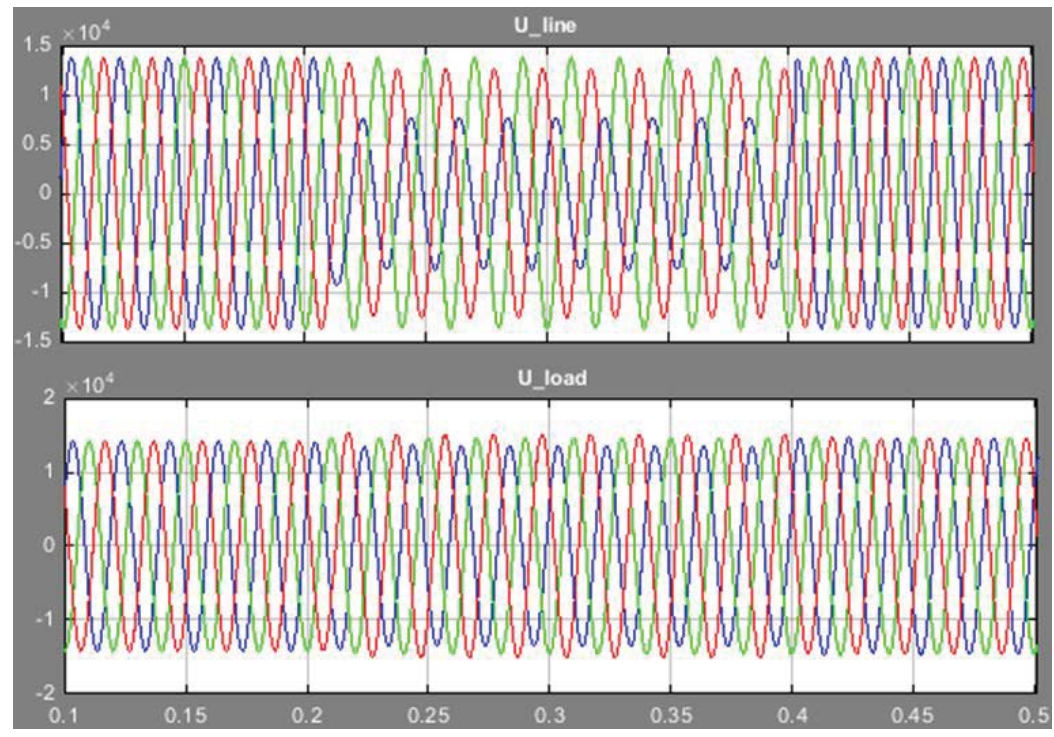

Figure 13: Mains and load voltage with single-phase voltage dip

\section{RESULTS}

Analysis of the dynamic compensation device showed the effectiveness of voltage dips eliminating when it is turned on sequentially. The features of switching on the DCPN at various voltage levels are considered, on the basis of which the best location of the dynamic compensator in the network is determined - the distribution network of medium voltage of 6-35 kV. The synthesis process of the automatic control system included the advantages of various compensation methods, thereby ensuring the operation of the installation with the greatest efficiency and energy saving.

\section{REFERENCES}

1. Vasin I.M. Calculation and mathematical modeling of operating modes of integrated electrical power systems of vessels with electric propulsion. // Modern problems of science and education. - 2014. - № 3.;

2. Abramovich, Boris \& Ustinov, D.A. \& Sychev, Yuriy \& Shkljarskiy, A.Y.A.. (2014). The methods of voltage dips and distortion compensation in electrical networks of oil production enterprises. 110-112.

3. Vorontsov A. G., Glushakov V. V., Pronin M. V., Sychev Yu. a. Features of control of cascade frequency converters / / journal of Mining Institute. 2020. №241. P. 37-45. DOI: 10.31897/PMI. 2020. 1. 37

4. Castro, karlamaria \& Alev, Ullar \& Aparicio, Xabier \& Arumagi, Endrik \& Ascione, Fabrizio \& Babin, Mihajlo \& Bianco, Nicola \& Burman, Esfandiar \& Roset, Jaime \& Corgnati, Stefano \& Cotana, F. \& D'Oca, Simona \& De Masi, Rosa \& De Stasio, Claudio \& Portillo, Luis \& Eric, Milos \& Erkoreka, A. \& Fabrizio, Enrico \& Ferrara, Maria \& Xaman, Jesus. (2017). Cost-Effective Energy-Efficient Building Retrofitting - Materials, Technologies, Optimization and Case Studies.
5. Belsky, Aleksey \& Dobush, Vasiliy \& Malarev, V. (2020). Electro Steam Thermal Complex Powered by Wind-Driven Generator for the Treatment of the Oil Formation's Bottomhole Area. Journal of Physics: Conference Series. 1441. 012020. 10.1088/1742$6596 / 1441 / 1 / 012020$

6. Bogdanovl .A., Veprikov A.A., Kasyanova A.N., Morenov V.A. Increase of energy efficiency of electrotechnical complexes of cogeneration plants for power supply of objects of oil and gas enterprises / International Research Journal. №: 12-5 (66) year: 2017. p. 59-63.

7. Yemelyanov, V., Nedelkin, A., \& Yemelyanova, N. (2020). Expert system software for assessing the technical condition of critical lined equipment doi:10.1007/978-3-030-37916-2 92

8. Kuzmin, P. A., Bukharina, I. L., \& Kuzmina, A. M. (2020). An investigation of the biochemical composition of norway maple (acer platanoides I.) in the conditions of technogenic stress. [Investigacao da composicao bioquimica do bordo da noruega (acer platanoides I.) nas condicoes de estresse tecnogenico] Periodico Tche Quimica, 17(34), 905-914.

9. Yemelyanov, V. A., Yemelyanova, N. Y., Nedelkin, A. A., Glebov, N. B., \& Tyapkin, D. A. (2019). Information system to determine the transported liquid iron weight. Paper presented at the Proceedings of the 2019 IEEE Conference of Russian Young Researchers in Electrical and Electronic Engineering, EIConRus 2019, 377-380. doi:10.1109/EIConRus.2019.8656693

10. Yemelyanov, V. A., Nedelkin, A. A., \& Olenev, L. A. (2019). An object-oriented design of expert system software for evaluating the maintenance of lined equipment. Paper presented at the 2019 International Multi-Conference on Industrial Engineering and Modern Technologies, FarEastCon 2019, doi:10.1109/FarEastCon.2019.8934414 
11. Testimony 2019611491 Russian Federation. Certificate of official registration of the computer program. simulation model of automatic control system for the installation of dynamic compensation of voltage dips / B.N. Abramovich, I.A. Bogdanov, V.I. Malarev; Applicant and copyright holder Federal State Budgetary Educational Institution of Higher Education "St. Petersburg Mining University" (RU) - No. 20169610240; declared 01/10/2019; publ. 01/28/2019.
12. Abramovich, B \& Bogdanov, I \& Kopteva, Alexandra \& Malarev, Vadim. (2019). The system of trigeneration with binary cycle for use as an energy source for gas fuel. IOP Conference Series: Materials Science and Engineering. 643. 012092. 10.1088/1757899X/643/1/012092. 